\title{
Revisiting Long-run Relations in Power Markets with High RES Penetration
}

\author{
Angelica Gianfreda ${ }^{\mathrm{a}}$, Lucia Parisio ${ }^{\mathrm{b}}$, Matteo Pelagatti ${ }^{\mathrm{b}}$ \\ ${ }^{a}$ Energy Markets Group, London Business School, London, UK \\ ${ }^{b}$ DEMS, University of Milano-Bicocca, Milan, Italy
}

\begin{abstract}
Electricity generation from renewable energy resources (RES) has become increasingly significant to reach EU and emissions reduction targets. At the same time, one of the main EU policy goals has been the creation of a common internal energy market for Europe. In this paper, we focus on these two issues previously studied separately, considering their possible interactions. We first analyze the long-run relationship between day-ahead electricity prices and fuel prices (natural gas and coal) looking at two samples of years characterized by low and high RES penetration, then we explore the integration of EU markets.

We show that the electricity-fuel nexus found over 2006-2008 changed dramatically over 2010-2014 for the majority of countries considered. In particular, the long-run dependence of electricity from gas and coal prices is much lower in recent years. Furthermore, our results confirm that the considered EU countries are becoming less integrated as RES-E increases. Our findings suggest that nationally implemented policies to support renewables are successful in increasing RES penetration, but they have lessened the linkage among EU markets, then making integration more difficult to obtain.
\end{abstract}

Keywords: Electricity, Natural Gas, Coal, Internal Energy Market (IEM), Overlapping Regulation

\section{Introduction}

Electricity generation from renewable energy resources (RES-E) has become increasingly significant all around the world to meet planned targets on emissions reduction. REN21 (2015) provides a comprehensive and timely overview of RES market, industry, investment, and policy developments. In the European Union, at least 20\% of the final energy consumption will have to be covered by RES by 2020 and this share will have to increase at least to $27 \%$ by 2030 (see EU (2009) and EU Commission (2014a)). The Renewable Energy Progress Report issued in 2013 states that the EU member countries have been initially successful in the implementation of the Directive, but then the difficulty of removing key barriers to renewable energy growth has decelerated the progress towards targets. Indeed in 2013, RES

\footnotetext{
*Corresponding author at: Energy Markets Group, London Business School, Regent's Park, London Email addresses: agianfreda@london.edu (Angelica Gianfreda), lucia.parisio@unimib.it (Lucia Parisio), matteo.pelagatti@unimib.it (Matteo Pelagatti)
} 
faced uncertainty and declining policy support not only in European countries but also in the United States, where grid constraints and a scenario of low gas prices made RES less profitable than in the EU. However, in the last ten years there were further positive developments which made RES more and more affordable due to continuous technological advances, falling prices, and financial innovations ${ }^{1}$. As a result, an increasing number of wind and solar power projects are being built around the world and the utilization of electricity from these sources, as well as from all other RES, can play a significant role in reducing country dependence on imported fossil fuels and in mitigating the global warming by reducing greenhouse gas emissions $^{2}$.

The world-wide promotion of RES-E generation has increased the complexity of the management of electricity system, given that wind energy (and solar to less extent) is highly variable and only partially predictable. Therefore, intermittency and the not-easily-storable nature of electricity have important implications for balancing supply and demand and any imbalance can cause large and sharp price changes especially when RES units are not uniformly spread in a territory and cause zonal congestions. The impact of RES-E production in different power markets may also produce spillover effects in neighboring countries. RES-E production might help market convergence or, on the contrary, it might obstacle the market convergence process. The creation of a common EU internal electricity market is the other fundamental pillar of EU energy policy. Integration is eased by the harmonization of market and technical rules, by an increase in the amount of interconnectors and most importantly by an economically efficient use of the interconnection capacity. Regulation 1228/2003/EC and $714 / 2009 / \mathrm{EC}$ introduced some fundamental guidelines for the management of cross-borders flows, based on common and economically efficient market rules. The market coupling mechanism has been introduced to efficiently use cross-border capacity between two neighboring areas. This mechanism considers the bids and asks of two or more power exchanges and allocate them taking into account cross-border transmission capacities ${ }^{3}$.

The goal of our paper is to analyze whether policy support toward RES-E generation implemented in most EU countries in the last years has slowed down the integration process of electricity markets that began soon after the liberalization of the industry and the opening of wholesale power markets in EU countries.

Several studies have analyzed the impact of RES on electricity prices, see among others

\footnotetext{
${ }^{1}$ As consequence, the recent report clearly states that "the EU and the vast majority of Member States are making good progress and 25 Member States are expected to meet their 2013/2014 interim targets, which correspond to the projected share of $15.3 \%$ of renewable energy in 2014 in the gross overall energy consumption; see EU Commission (2014b).

${ }^{2} \mathrm{CO} 2$ emissions doubled worldwide from 1971 to 2010, when the $44 \%$ of them came from the electricity sector. See IEA (2013)

${ }^{3}$ We already assisted to the coupling of the Nordic markets with Sweden and Norway (1996), followed by Denmark (1998) and Finland (2000), Estonia, Poland, and Latvia (June 2013); the Central Western European (CWE) region with its trilateral coupling between France, Belgium and the Netherlands (2006), and Germany (2010). The Central and Eastern Europe (CEE) characterized by market coupling between the Czech Republic and Slovakia (2009), and Hungary (2012). Poland is also coupled with Sweden and Italy with Slovenia (2011), Austria (2014) and France (2014). Finally, on February 2014 the CWE and the Nordic region were coupled with the UK and Ireland, forming the North Western Europe (NWE) market and on May 2014 also the South-West European Market (Spain and Portugal) was coupled with North-Western Europe.
} 
Gelabert et al. (2011), Woo et al. (2011), Mauritzen (2013) and Ketterer (2014). However, previous contributions did not consider the effect of RES-E on long-run price relations and markets integration. We expect that EU policies towards market integration have eased the market convergence process at least in areas sharing sufficient transmission capacities. Despite few circumstances testifying the lack of import capacities ${ }^{4}$ or the unavailability of nuclear power ${ }^{5}$, the mechanism of market coupling does not eliminate price differentials across neighboring markets and there is no clear evidence of convergence in EU wholesale electricity prices. The issue of interdependencies in power prices has been deeply and extensively studied using cointegration analysis for assessing EU market integration, as in Bosco et al. (2010), Bunn and Gianfreda (2010), Balaguer (2011), Lindström and Regland (2012), Bollino et al. (2013), Huisman and Kilic (2013), Castagneto-Gissey et al. (2014) and de Menezes and Houllier (2015) among many others.

Since market integration appears to be strongly influenced by the electricity mix among other potential price drivers, we provide empirical evidence on the effect of RES-E in two directions. On one side, we aim at showing that national policies to increase RES shares in the electricity mix have consequences on the long-run relations of electricity/fuel prices. On the other side, we want to test if the changing relationship of electricity prices with fuel prices has affected the degree of EU electricity market integration. We claim that the lack of long-run relations among fuel and electricity prices, induced by high RES penetration achieved with different local support policies, produced a reduction of the EU electricity market integration. This happens because RES have inverted and/or canceled the traditional relation between electricity and its fuels which was driving the common trend and producing convergence of EU wholesale electricity prices as documented in Bosco et al. (2010)

We consider a time horizon from 2006 to the end of 2014, which is characterized by a progressive increment of RES generation from low, or even absent, to high penetration. In this connection, we divide the time series into two samples 2006-08 (low RES penetration) and 2010-14 (high RES penetration). We examine EU markets with different mixes, common borders and similar price-setting processes (Germany, France, Spain, Italy, The Netherlands and Great Britain) and Texas, as US benchmark market for a broader international comparison. In these markets wind and/or solar generation play the same role as negative demand and are expected to affect peak periods and average spot prices, fostering a substitution effect between RES and fuels, as suggested by Clò and D'Adamo (2015).

The analysis conducted in our paper may therefore suggest policy implications related to the possibly unwanted interaction of two EU energy objectives: the support to RES and the creation of the IEM. We indeed expect firstly that a weak relation between electricity, gas and coal prices should occur in the second sample 2010-14. So we expect that when RES penetration increases the influence from fuels to electricity prices is reduced. Secondly, we guess that the degree of market integration should be reduced in the second sample, especially in hours with higher amounts of RES-E generation.

\footnotetext{
${ }^{4}$ Dutch power prices exhibited an average premium of $14 € / \mathrm{MWh}$ with respect to German prices in 2013, when there was insufficient import capacity for excess German solar and wind generation (EU Commission, 2014a).

${ }^{5}$ Belgian prices decoupled from the CWE region in 2012 because two nuclear reactors were permanently offline (EU Commission, 2014a).
} 
The paper is structured as follows: Section 2 provides a description of the background of our analysis and an overview of EU markets characteristics whereas Section 3 describes the data and the pre-processing techniques used. Results of the dynamic analysis of the considered electricity-fuel nexus and market integration are presented in Section 4. Finally, Section 5 concludes.

\section{Background and Literature Review}

Wholesale electricity prices are influenced by supply and demand side drivers. Supply side drivers include the composition of the power generation mix, the amount of generation compared to consumption, the availability of power imports and exports and other factors as carbon emission allowances. Demand side drivers include the electricity needs of households and firms and they are influenced by energy policies and general economic conditions.

Looking at the supply side, several factors have simultaneously contributed to cap wholesale prices such as the reduction of coal prices since the beginning of 2011 (mainly because US, the third exporter to EU, increased its hard coal exports as reaction of the increasing internal consumption of gas) and the stabilization of natural gas prices since the beginning of 2012 (after a significant growth in 2010 and 2011). Finally, the structural oversupply of EU emissions trading scheme (ETS) allowances has depressed carbon prices ${ }^{6}$.

All together, we assisted to an increased profitability of coal-fired power plants in the same time span when RES were gaining ground. In 2012, EU RES-E reached 799 TWh with an increase of more than 13\% compared to 2011. Among renewable electricity sources, hydro power is the most important one and accounts for $46 \%$ of renewable electricity generation into the EU. Between 2011 and 2012 the electricity from wind registered a growth of about $14 \%$, the solar energy growth was of more than $50 \%$, with a share in renewable electricity generation reaching $9 \%$ and finally electricity from biomass and waste grew of about $12 \%$.

However, the levels of RES penetration differ across countries. For instance, there is an important contribution of hydro in Spain, Portugal, Sweden, Austria, Norway and Switzerland, i.e. in countries where the amount of rain significantly influences the generation costs and wholesale power prices. In other countries where wind and solar power generation rapidly increased, there was a reduction of average electricity prices ${ }^{7}$. Several authors have shown the relationship between RES-E and electricity prices. Gelabert et al. (2011) presented an empirical analysis of the relation between electricity prices and prevailing technologies in Spain, accounting for the total electricity produced by RES and hydro. They show that generating electricity by RES and cogeneration reduces the electricity prices, and consumers should expect an average payment reduction significantly lower than the annual cost for RES support. While the cost of support has increased (mostly due to the introduction of solar PV) in period 2005-10, the wholesale price reduction has diminished. As a consequence, serious

${ }^{6}$ EU Emission ETS allowance prices reached $15 €$ /tonnes of CO2 equivalent in June 2011 but fell below $5 € /$ tonnes in 2013, on average (EU Commission (2014b)).

${ }^{7}$ On the contrary, Italy, Ireland, the United Kingdom and the Netherlands were among the countries with the highest prices in 2013, because of insufficient interconnection capacities (Italy and Ireland) or because of the dominant expensive natural gas in setting the electricity system marginal price (The Netherlands and UK). 
doubts emerge on the sustainability of electricity market structures with a large renewable share since the decreasing trend in electricity prices may be incompatible with the necessary remuneration of non-renewable sources.

The relationship between wind and electricity prices, taking also into account its effect on congestion and external market interconnections, has been explored in several cases such as Texas, Australia, Spain, Denmark, Norway, United Kingdom, The Netherlands and Germany. More specifically, the effect of wind generation on electricity price variability has been explored for Texas by Woo et al. (2011), who prove that an increase in wind generation reduces electricity prices but increases their variance. Similar conclusions are found by Ketterer (2014) in Germany. Woo et al. (2011) develop a model for wind-price interactions into interconnected zones, and then providing evidence that wind generation tends to cause time-dependent zonal price divergences in Texas. Further additional effects of import and export flows have been investigated by Mulder and Scholtens (2013) in The Netherlands. Mauritzen (2013) explores the relations between actual wind power and electricity trades between Denmark and Norway. Cruz et al. (2011) compare the predictive accuracy of several forecasting models for Spanish day-ahead spot prices and show that the inclusion of hourly electricity load and wind generation forecasts significantly improves price forecasts, mainly because wind generation has become a fundamental price driver in Spain. More recently, considering an hypothetical future energy scenario in which electricity will be completely generated by RES and covered by storage power plants, Brunner (2014) suggests that the expected effect of RES is to produce a general price level reduction in addition to changes in the volatility and into the structure of spot prices, given the dependence of supply on intermittent generation.

In this scenario of significant growth of RES sources in markets still characterized by strong dependency on fossil fuels, the wholesale price dynamics is expected to evolve. We believe that the fuel-electricity price nexus is likely to reflect this evolution, that is the dynamic relationship among electricity prices and fuel prices (gas and coal) might be significantly modified. Therefore, we analyze the effect of RES on long-run relations between electricity and fossil fuels in Germany, France, Spain, Italy, The Netherlands, and Great Britain.

The markets considered are governed by different factors and regulatory provisions. For example, in German EPEX negative pricing is admitted ${ }^{8}$, in Spain there is a high share of wind penetration, whereas in Italy the high solar penetration, in connection with high hydro shares and no nuclear power, produces important implications in terms of balancing markets, as highlighted by Gianfreda and Parisio (2015). In addition, we consider cases of large interconnection capacity (France) and cases of limited transmission capacity ${ }^{9}$. Finally, we consider a broader international context including Texas in our sample. We believe that Texas is a very interesting case since it is the US top country for new wind power capacity installed and wind penetration in $2014^{10}$. At the same time Texas registered an increase in

\footnotetext{
${ }^{8}$ This happens not just in Germany, but also in Texas as well as in Australia, where sometimes negative prices occurred long time before the introduction of RES. A negative market price allows generators to pay the cost of staying "online" instead of incurring in a higher startup cost.

${ }^{9}$ In France $12 \mathrm{GW}$ are available for exporting and $8 \mathrm{GW}$ for importing. France is the worldwide biggest exporter of electricity with 47.6 TWh in 2013, see IEA (2013)

${ }^{10}$ According to AWEA (2014), the total wind power capacity was of $14 \mathrm{GW}$ and the penetration was around
} 
electricity demand since 2009 so it can provide an interesting comparison with respect to the EU countries which experienced a longer time of demand decrease.

Power generation mixes and their evolution though years have been depicted in Figures 1 and 2, that show the shares of technology generation, and RES penetration levels together with the yearly dynamics of demand (in TW on the right axis). The incomplete information about the Dutch generation mix led us to use the information contained in EU Commission (2014b).

German power generation mix was largely dominated by mixed fuels, nuclear power and coal until 2011 when the German Parliament decided to phase-out nuclear power generation by 2022. This decision is likely to leave ground to coal and natural gas. At the same time, RES become more and more important with a share higher that $20 \%$ over total generation in 2013 and 2014. Looking at figures about RES penetration, we observe a slight increase in wind energy through years, but a sharp increase in both solar and biomass in the most recent years. Spanish electricity production looks more fragmented in these recent years, moving from the predominant nuclear share observed in 2005 (and equal to 46\%) to a more RES oriented generation with a total share of more than $40 \%$ from 2010 . We observe similar shares of nuclear, coal and gas in the last two years. Remarkably, Spain shows the highest RES penetration over the markets considered, with RES-E covering on the whole more than $15 \%$ of consumption. Similar dynamics for RES penetration is observed in Italy, where solar suddenly covered more than $7 \%$ of Italian demand for electricity. Besides wind and solar increasing shares in power generation, the Italian mix does not exhibit dramatic changes but we notice that the share of conventional thermal power plants dropped from $80 \%$ at the beginning of 2012 to $54 \%$ at the middle of 2014. Among fossils, gas primarily drives the generation, followed by coal, oil and mixed fuels whereas no nuclear generation is available. Opposite situation is found in France, where the energy production has been almost constantly granted by nuclear power for more than $70 \%$, with very low shares for coal, gas and other fossil fuels which have been further reduced by the increase of RES, even if they show a low market penetration. The British power generation mix is dominated by gas-fired units (with a share around 40.2\%), solid fuels (around 20\%) and to a lesser extent by nuclear energy (around 10\%). The renewable share of generation is around 10\%, with a penetration of almost 5\%. The Texan system is based on similar shares of coal and gas generation (around $40 \%$ ) and on a low share of nuclear power. Texas produces more wind power than any other US state. Indeed, wind feed-in accounted for $4.4 \%$ of the US electricity generation and $9 \%$ of the Texan generation in 2014, with installed capacity of 15,635 MW. Dutch power generation mix is dominated by gas-fired units (with a share of $63.5 \%$ in 2011) and a significant amount of coal-fired production capacity (solid fuels amounted to $18.9 \%$ in 2011). RES represented a $10.9 \%$ share and nuclear power was less important with a share of 3.6\%. The energy consumption was based mainly on fossil fuels in 2012, notably natural gas, crude oil and petroleum products, and to a lesser extent solid fuels. Renewable and nuclear energy exhibited values of penetration equal to $4.3 \%$ and $1.2 \%$, respectively (for further details see EU Commission (2014b)). The Netherlands is involved in several successful market coupling projects and two interconnectors (BritNed with the UK, and NorNed with Norway) allows

$10 \%$ in 2014. 

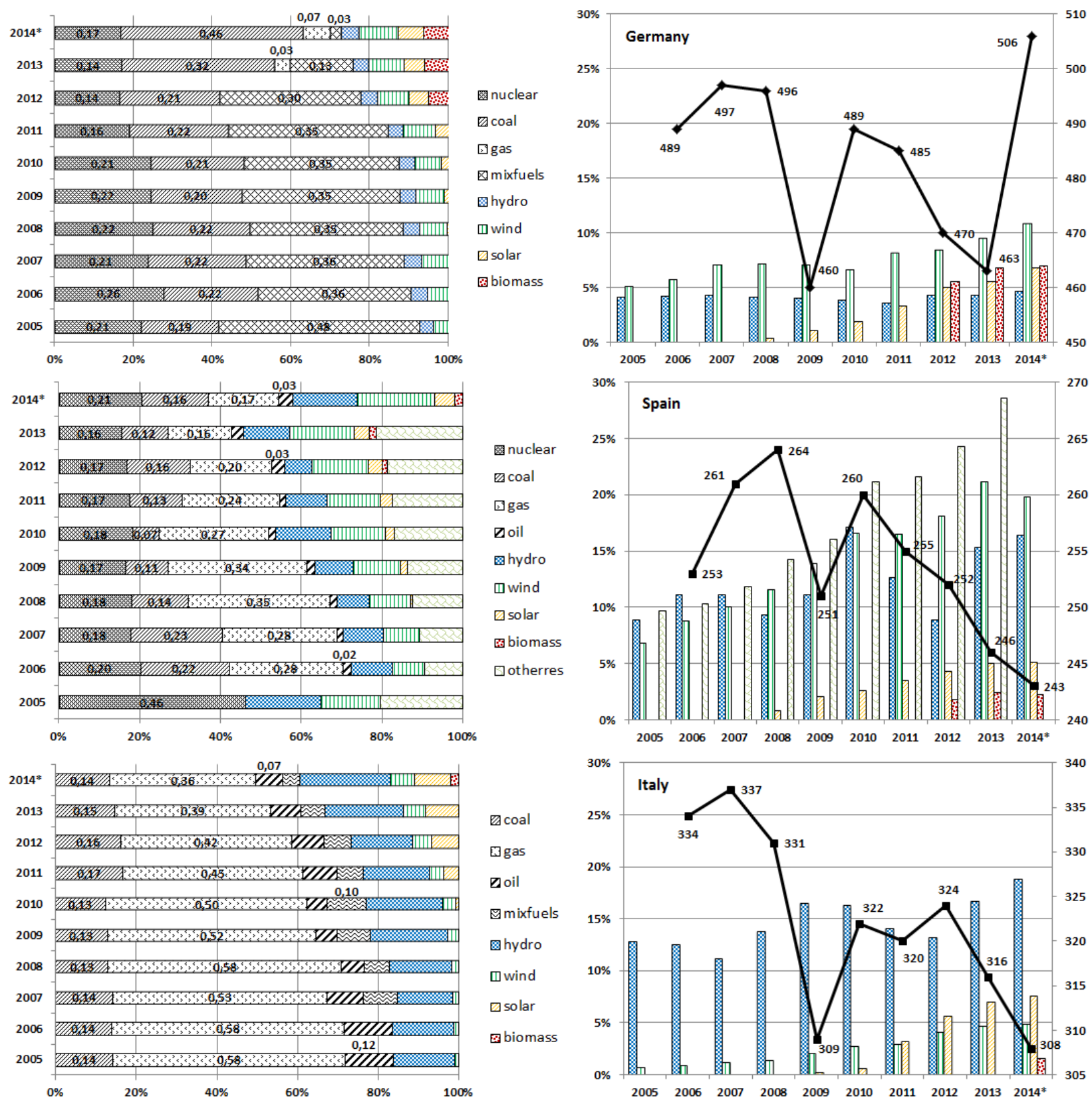

Figure 1: Shares by technology generation (on the left), and RES penetration together with Demand levels in TW (on the right) in Germany (first row), Spain (second row), Italy (third row), and France (last row) Data Source: ENTSO-E. Data for 2014 is provisional.

for new cross-border allocations.

Complex regulatory frameworks have been adopted at national levels to promote RES-E and achieve the EU targets ${ }^{11}$. As suggested by Böhringer and Rosendahl (2010), the regu-

\footnotetext{
${ }^{11}$ In Germany, electricity from renewable sources is supported through a feed-in tariff. The criteria for eligibility and the tariff levels are set out in the Act on Granting Priority to Renewable Energy Sources (EEG). According to this Act, operators of renewable energy plants are statutorily entitled against the
} 

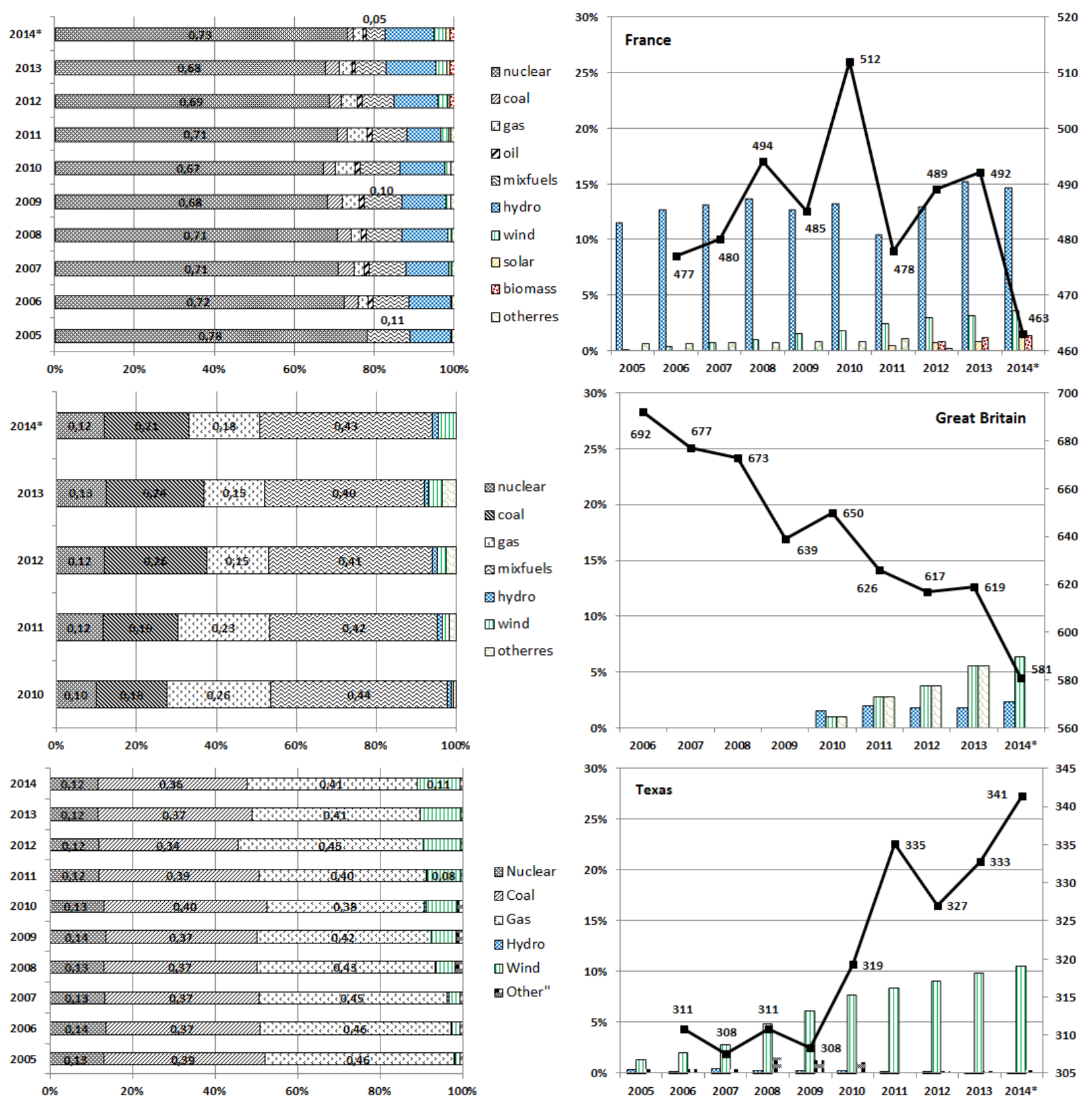

Figure 2: Shares by technology generation (on the left) and RES penetration together with Demand levels in TW (on the right) in France (first row), Great Britain (second row) and Texas (last row) - Data Source: ENTSOE \& ERCOT. EU Data for 2014 is provisional. "Other" in Texas includes petroleum coke, landfill gas, biomass solids, biomass gases, solar and any unknown fuel; plus import/export flows.

grid operator to payments for electricity exported to the grid. The EEG also introduced the so-called market premium and the flexibility premium for plant operators who directly sell their electricity from renewable sources. Moreover, low interest loans for investments in new plants are provided for by different programs. Plants for the generation of electricity from RES shall be given priority connection to the grid. Furthermore, grid operators are obliged to give priority to electricity from renewable sources when purchasing and transmitting electricity. In Spain, the main support scheme was the "Régimen Especial"operated until 
lations for promoting the "greens" and reducing the "dirtiest" may produce unexpected and unwanted results because of their overlapping. Moreover, as anticipated by de Menezes and Houllier (2015), a fully coordinated EU energy policy is necessary in order to avoid unintended interactions between supranational and national policies, given that each individual country may affect the neighboring ones. On the one side, national supply is procured by local policies determining the internal energy mix in each country, whereas, on the other side, these same policies may represent obstacles against the creation of an internal energy market that actually needs strong coordination.

Indeed, previous studies provided unclear evidence through years. Bosco et al. (2010) analyzed the integration of central European markets (France, Germany, the Netherlands and Austria) by means of a robust multivariate long-run dynamic analysis, showing a trend of high integration appearing to be common with gas, but not with oil prices over the period ending in March 2007. Bunn and Gianfreda (2010) present empirical results about the integration of the French, German, British, Dutch and Spanish power markets at different time horizons for sample period from July 2001 to July 2005. They found evidence of market integration increasing over time, despite an underlying inefficiency in each market with respect to the forward and spot price convergence. Causality tests, cointegration and impulse-response techniques, for both price levels and volatilities, were performed indicating less influence of the size and proximity of neighboring markets as compared to other studies. More integration is found at baseload than peak, and, surprisingly, less integration in forwards than spot prices. Lindström and Regland (2012) analyzed data for a subsequent period (2005-2010), again for spot and forward markets, and confirmed the previous finding of partial integration. In line with these results are those obtained by Balaguer (2011) who found high integration between Danish and Swedish prices and on the opposite price divergence among French, German and Italian prices during sample period 2003-2009. Bollino et al. (2013) analyzed the price convergence among Austria, Germany, France and Italy between 2004 and 2010 proving that German electricity prices were signals to the other neighboring markets. Using regime switching models over the period 2003-2010, Huisman and Kilic (2013) observed similar parameter estimates when modeling Belgian, Dutch, French, German and Nordic day-ahead prices. More recently, Castagneto-Gissey et al. (2014) explored the time-varying interactions among markets studying 13 EU electricity markets from 2007 to 2012 by means of

the end of 2011. Afterwards, no other support schemes were put in place apart from a tax regulation system for investments related to RES-E plants. In Italy, there is a combination of premium tariffs, feed-in tariffs and tender schemes; tax regulation mechanisms are also in place for investment in RES-E plants. Furthermore, interested parties can make use of net-metering. RES units are granted priority despatch. In France, there are both feed-in tariffs and tax benefits. The use of the grid for the transmission of electricity from renewable sources is subject to the general legislation on energy. There are no special provisions for electricity from RES. In Great Britain, RES-E is supported through feed-in tariffs, Contracts for Difference, quota systems and tax regulation mechanisms. RES-E electricity is connected to the grid under the principle of non-discrimination, RES-E plant operators are granted the right to access the grid and grid operators are obliged to expand the grid if this is necessary to accept all generated RES E from a plant. In The Netherlands, the main support instrument is the $S D E+$ premium feed-in scheme (a premium on top of the market price to compensate for the difference between the wholesale price of electricity from fossil sources and the price of electricity from renewable sources), together with loans and various tax benefits. Moreover, net-metering applies to small installations. Further details on RES-E supporting mechanisms within EU are available at http://www.res-legal.eu. 
Granger-causal networks, providing evidence of increased association but with an overall lack of market integration. Therefore, it appears that market coupling and new interconnector commissioning which occurred after the implementation of the Third Energy Package did not provide the expected results. de Menezes and Houllier (2014) studied the European electricity market integration using data from nine EU markets for the time period 2000 to March 2013 and adopting a time-varying fractional cointegration analysis for both spot and one-month ahead electricity prices. They investigated not only whether wholesale prices were converging, but also whether the pace of convergence could have been affected by special events on the supply side (such as the $21^{\text {st }}$ November 2006, when the Trilateral Market Coupling went live and the Belgian power exchange was launched; the launch of the NorNed interconnector on 6 May 2008; or the removal of 40\% of German nuclear capacity on 6 August 2011). Electricity spot markets which are geographically close or well-connected have been found to have longer periods of price convergence. However, overall electricity spot prices were not increasingly converging and spot price dispersion could not be related to market integration. Using shortrun dynamic correlations and long-run fractional cointegration analysis, de Menezes and Houllier (2015) studied the time-varying associations between electricity prices and German wind power, observing greater spot price and volatility associations across interconnected markets and less long-run integration of German and neighbors markets together with a decreasing speed in mean reversion. ${ }^{12}$

Therefore, given all previous analyses which did not consider the interaction between RES-E penetration and the integration of electricity markets, we are going to provide empirical evidence that the achievement of EU renewable targets by single countries indirectly affects the internal energy market. We show that local policies may interact with the EU supranational policies and actually produce results diverging from EU planned targets.

\section{Methodology}

\subsection{Data Description}

We consider the weekday (average) wholesale electricity prices of the following countries: France (FR), Germany (DE), Great Britain (GB), Italy (IT), The Netherlands (NL), Spain (ES), and Texas (TX). Data have been collected directly from market exchanges and Datastream (Reuters, 2013) and all series are quoted or converted in $€ / M W h$. In addition, we consider coal prices and the ICE $\mathrm{UK}^{13}$, for EU, and the Henry Hub, for US, as reference prices for natural gas, all converted in $€ / M W h$. We additionally consider another important driver of electricity prices, that is, the demand for electricity, even if measured by a proxy, such as

\footnotetext{
${ }^{12}$ They found that the cointegrated pairs differ after 6 August 2011 and no market was integrated with Germany, while before that date Netherlands and Switzerland were. They also found an increasing integration between Belgium, The Netherlands, NordPool and France, rejecting overall the hypothesis of less EU integration.

${ }^{13}$ It represents a pure hub benchmark against other hybrid prices containing hub and oil indexation elements, as in EU Commission (2014b). Furthermore, we do not disentangle between the wholesale gas prices across the EU, because of strong correlation across the EU hub prices from 2010-2014. Only two exceptions were the Italian PSV and French PEG South: but the former had progressively aligned with continental hub prices, whereas the latter followed an opposite evolution, diverging from the more traded PEG North prices, because of low levels and capacities of gas storage internal to the French market (EU Commission (2014b)).
} 
the system load. To account for different configurations of demanded quantity and supply conditions, we consider the daily prices of electricity determined at specific hours: we analyze the 4th, 13th, and 19th hour of each day. Indeed, from the inspection of the intra-daily profiles of load ${ }^{14}$, it is possible to detect the following facts: i) the yearly average demand for individual hours moved across years by simple up- and down-shifts without changing its shape $^{15}$ in any of the considered markets and years; ii) electricity demand generally shows its highest values during peak hours (i.e., from 8 to 20) and the opposite for off-peak hours; iii) for all markets the hours 4, 13 and 19 clearly represent situations in which we observe, respectively, the lowest load (h4), mid-day peak (h13) and late afternoon peak (h19). As shown for Germany in Figure 3, these hours are of particular interest for the following reasons: at hour 4 we do not expect significant changes brought about by the introduction of RES generation because both demand and RES production are low, although RES may slightly reduce the nexus between drivers and electricity prices; at hour 13 we expect a significant change brought about by the introduction of RES generation, since demand is very high and RES generation at its maximum, with the peak of solar production summing to wind generation; at hour 19 we expect some changes brought about by the introduction of RES generation, because the demand is still high, photovoltaic generation is low, but wind is still contributing to the total generation.

It must be emphasized that we consider hourly prices determined on day-ahead markets, and not on balancing markets, therefore, we cannot actually see the real-time relations between electricity and gas prices induced by the required up- or down-regulation to back-up RES-E generation. Still, RES-E reduces the production of conventional units, as renewable generation increases through years and consequently reduces the influence of price drivers on day-ahead electricity prices. Furthermore, the general documented reduction of electricity demand in almost all EU countries must correspond to a reduction in the electricity-fuel nexus. We generally expect to observe a reduced gas/coal influence on electricity prices because of the contraction of demand in Germany, Spain, Italy, France, and Great Britain. Obviously, markets with flat or increasing trend for demand provide more reliable (controlled) results. For this reason, we look at The Netherlands and Texas as control cases because in the former case (NL) demand was stable around 110TW across years, whereas in the latter market (TX) demand increased over time.

\subsection{Data Pre-processing}

It is a well known fact that wholesale electricity prices are very far from behaving like Gaussian processes and, thus, least-squares based econometric methods tend to fail, unless

\footnotetext{
${ }^{14}$ We produced profiles for all markets, but for lack of space we report just the German ones as an example; the others are available on request. We observed similar dynamics for all countries with some differences: Germany, Netherlands and Italy show two clusters of load maxima: one during peak hours in the morning and the other at mid-afternoon; Spain and Great Britain show the highest values during peak hours in the late afternoon. The Texan profile is rather peculiar: its demand rises slowly and reaches its max during the 19th hour before falling sharply at night. Thus, the hours on which we base our analysis are very relevant in all considered markets.

${ }^{15}$ The movement of average hourly levels is induced by the variation of yearly total demand. Looking at ENTSO-E total load data, we observe a negative trend (started in year 2010) in Great Britain, Spain, Italy and Germany. Whereas in Texas we assisted to a growing demand of electricity through all years.
} 

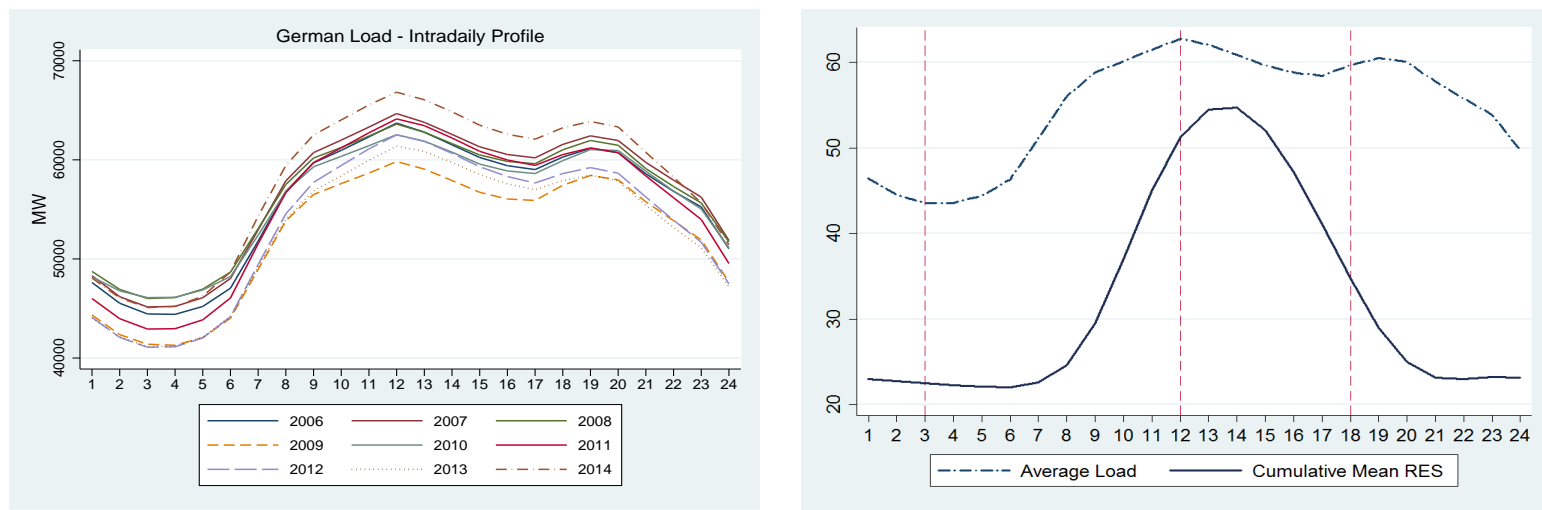

Figure 3: Intra-day load profiles for Germany together with a representation for simultaneous dynamics of average load and RES generation (obtained as wind plus solar photovoltaic feed-in).

the most "extreme" features of these data are dealt with before the analysis. Furthermore, the data generating process of electricity prices can be viewed as the sum of a persistent component linked to the marginal costs of production and affected by the market structure plus an extremely noisy and leptokurtic component determined by short-term "shocks" such as strategies of the market participants, mismatch between the actual demand and its forecasts, plant maintenance, exceptional meteorological events, etc. From an econometric point of view, this structure of the data generating process tends to rule out all those methods based on autoregressions, such as the Augmented Dickey Fuller unit root test (ADF, Dickey and Fuller, 1979; Said and Dickey, 1984) and Johansen's cointegration tests. ${ }^{16}$

In order to enhance the signal-to-noise ratio and reduce the leptokurtosis of the electricity price time series, we process the data in two ways. First of all, as in Bosco et al. (2010) we use weekly median prices. The effect of taking the median is twofold: it reduces both the effect of the short-term noise and the presence of isolated within-week extreme observations. Secondly, we fit a simple random walk plus noise model to the weekly median prices and identify possible additive outliers using the auxiliary residuals as described by Harvey and Koopman (1992). The outlier found at time $\tau$ is then substituted with its expected value (i.e., the smoothed estimate $\mathrm{E}\left[y_{\tau} \mid y_{1}, \ldots, y_{\tau-1}, y_{\tau+1}, \ldots, y_{n}\right]$ based on the random walk plus noise model fitted excluding the identified outliers). This operation reduces the strong influence that aberrant observations have on least-squares procedures and further enhances the signal with respect to the noise. For natural gas and coal prices we use weekly medians without further processing. Figure 4 shows the dynamics of German weekly median prices before and after processing. Clearly, we see the importance of such pre-processing in taking care that extreme outliers are properly filtered out. Furthermore, the dynamics of EU electricity prices

\footnotetext{
${ }^{16}$ In order to see why, consider the simple data generating process $y_{t}=\mu_{t}+\epsilon_{t}$, with $\mu_{t}=\mu_{t-1}+\eta_{t}$, and $\eta_{t}$ and $\epsilon_{t}$ white noise processes with variances $\sigma_{\eta}^{2}$ and $\sigma_{\epsilon}^{2}$. The ADF and Johansen's tests are based on the difference of the data, which in our simple model look like $\Delta y_{t}=\Delta \mu_{t}+\Delta \epsilon_{t}=\eta_{t}+\epsilon_{t}-\epsilon_{t-1}$, which is a moving average process (MA) of order 1 whose coefficient approaches -1 when the signal-to-noise ratio $\sigma_{\eta}^{2} / \sigma_{\epsilon}^{2}$ gets small. Thus, when the noise component $\epsilon_{t}$ dominates, the near-to-unity root of the MA process tends to cancel out with the unit root of the $y_{t}$ process and the ADF fails to find the unit root in $y_{t}$. Similarly, Johansen's test finds more cointegration relations than there are.
} 


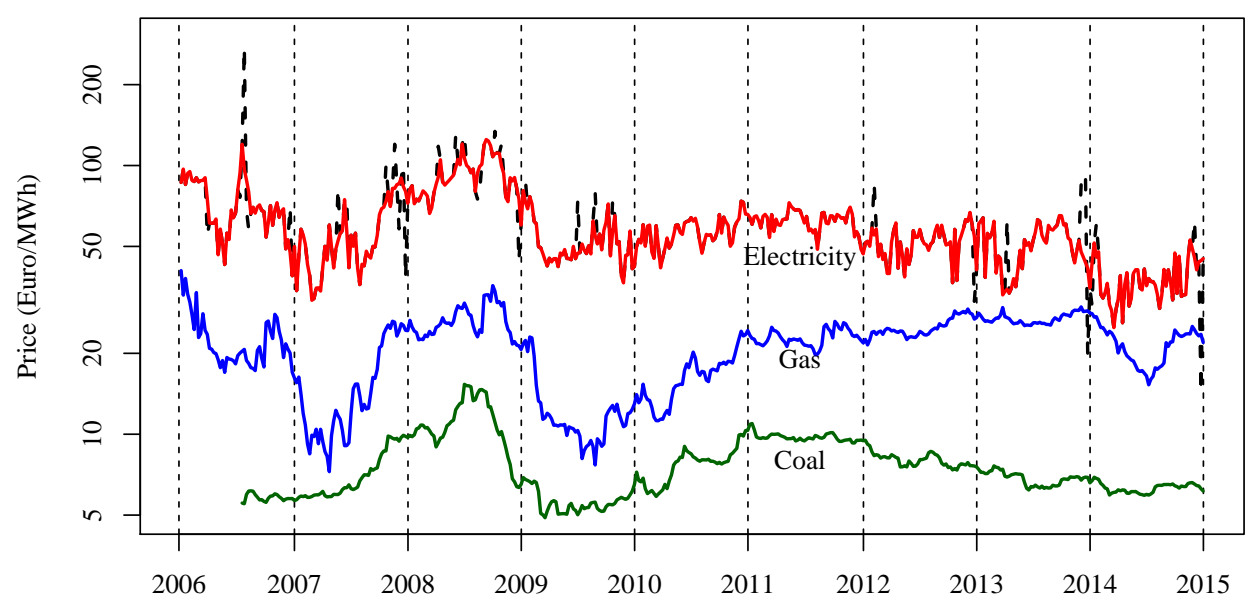

Figure 4: German weekly median electricity prices at hour 13 without (dashed line) and with (line) preprocessing, plotted together with weekly median prices of gas and coal.

shown in Figure 5 clearly exhibits a common change starting from mid 2009. This allows us to divide our sample into two subsets and implement a dynamic analysis on years 2006-2008 and 2010-2014.

\subsection{Methods}

All time series of electricity, coal and gas prices were tested for a unit root using the ADF test over the full-sample 2006-2014, and the conclusion is that all time series are integrated of order one (i.e., I(1)). Since our conjecture is that the strong increment of RES electricity generation induced changes in the relation between electricity prices and fuel prices, all the following analyses have been carried out separately on the two subsamples, 2006-2008 and 2010-2014. Moreover, we analyze the time series of hour 4, 13 and 19 individually.

For each country, for each considered hour and for each subsample, we tested for the presence of cointegration among the logarithms of electricity and fuel (i.e., gas, coal) prices. Johansen's test results were similar for all the countries, hours and subsamples: the hypothesis that all time series triplets have one long-run relation (i.e., one cointegration vector) cannot be rejected. Thus, the strong increment of RES generation in the second subsample did not have the effect of annihilating the presence of a long-run equilibrium among electricity, gas and coal prices. In order to understand if and how the long-run relations among these prices have changed in the second subsample, we estimated a vector error correction model (VECM) for each country, coherently with the number of cointegrating relations found by Johansen's test. For all countries and subsamples the hypothesis of (weak) exogeneity of electricity prices was rejected. This means that hydrocarbon sources remain drivers of the long-run dynamics of electricity prices also in the subsample 2010-2014. Moreover, gas prices resulted (weakly) exogenous in the great majority of the estimated VECMs. Thus, natural gas tends to determine the long-run levels of electricity and coal prices, without being influenced by those prices in the same time-span.

In this framework (VECM), the best way to assess the role that natural gas and coal prices play in influencing electricity prices in the long-run is by the forecast error variance decomposition (FEVD), which allows to determine how much of the forecast error variance of each of the variables can be explained by exogenous shocks to the other variables. Figures 

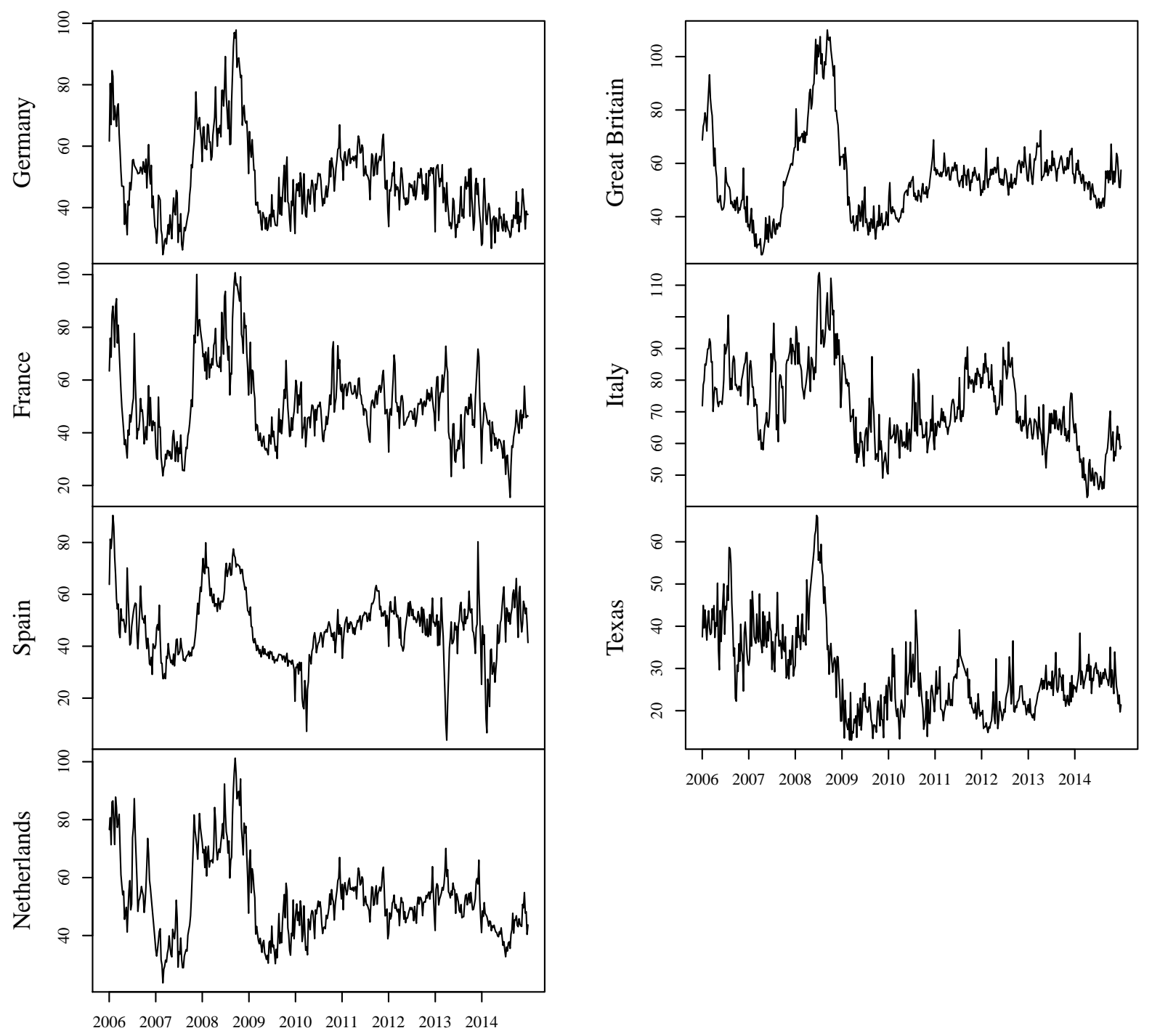

Figure 5: Weekly median prices (in €/MWh) for selected electricity markets from 2006 to 2014. 
11-12 depict the share of variance of future electricity prices explained by endogenous shocks (i.e., on electricity prices) and by shocks in gas and coal prices over a forecast horizon of 1 to 50 weeks. The detailed discussion of these plots is the argument of Section 4, however a quick visual inspection of the graphs is sufficient to realize that in the second subsample unexpected movements in hydrocarbon prices, and in particular natural gas prices, determine a much smaller share of unanticipated future electricity prices changes. Bosco et al. (2010) assessed the degree of integration ${ }^{17}$ of some European electricity markets and concluded that there was a core of central European countries whose electricity prices followed a common trend. This common trend was the effect of two factors: i) well interconnected markets, ii) the common price of fuel (natural gas in particular) in marginal generation units. Now, during the last years, some interconnecting lines have increased their capacity, but RES generation is influenced by local conditions and so one of the factors determining the wholesale price of electricity in each country is likely to have lost its role, at least at some hours. We assess if the strong growth of RES generation has affected the integration among European electricity markets testing the hypothesis that for any two countries $a$ and $b$ in our sample the ratio of their electricity prices is mean-reverting, that is, it has a constant mean toward which it always reverts in a relatively short time; formally, we test the hypothesis $H_{0}: \log \left(p_{a, t} / p_{b, t}\right) \sim$ $I(0)$. In fact, if two markets are integrated (strongly integrated in the terminology of De Vany and Walls, 1999; Bosco et al., 2010) the relative prices should be approximately constant (weak law of one price). This hypothesis has been tested using the well-known KPSS statistic (Kwiatkowski et al., 1992) and its outlier-robust version RKPSS (Pelagatti and Sen, 2013) and the results for each country pair, hour and subsample can be read in Table 2. Table 1 summarizes the number of times the strong integration hypothesis was not rejected among the 15 unique pairs that can be formed considering our 6 European countries. While at hour 4 the number of strongly integrated countries has increased (from 10 to 12) from subsample 2006-2008 to subsample 2010-2014, because of the low demand and the increased capacity of cross-market interconnections, for hours 13 and 19, when RES generation and demand are high, the number of strongly integrated markets is reduced (from 8 to 4-5).

\begin{tabular}{lrrrrrrr}
\hline & \multicolumn{3}{c}{ KPSS $(\alpha=5 \%)$} & & \multicolumn{3}{c}{ RKPSS $(\alpha=5 \%)$} \\
\cline { 2 - 3 } \cline { 7 - 8 } Sample & h4 & h13 & h19 & & h4 & h13 & h19 \\
\hline $2006-2008$ & 10 & 8 & 8 & & 10 & 8 & 8 \\
$2010-2014$ & 12 & 5 & 5 & & 12 & 4 & 5 \\
\hline
\end{tabular}

Table 1: Number of times the strong integration hypothesis was not rejected among all unique pairs of studied European countries.

\section{Results and Discussion}

\subsection{Impacts at National Levels: Dynamic Analysis of Electricity-Fuels Nexus}

Given the price dynamics on the international markets characterized by lower coal prices and high US natural gas supply, we expect more coal consumption in the EU versus a

\footnotetext{
${ }^{17}$ The term integration is here used with its usual meaning rather than with the econometrics meaning.
} 
greater US domestic consumption of natural gas. Hence we generally expect coal playing a leading role (according to the country generation mix) in the determination of EU day-ahead electricity prices in recent years and the opposite for Texas.

We consider RES penetration by implementing a dynamic analysis over two samples: the first one, 2006-2008, in which the share of RES was rather limited and the second one, 20102014, in which RES-E production significantly increased. Thus, we assume that, controlling for demand, the changes in the dynamics of day-ahead electricity prices are mainly caused by the increase in RES generation. To this aim, we have decomposed the forecasted variance of electricity prices in terms of forecasted variance of coal and gas prices, by looking at specific hours or levels of demand. In this way, we are able to explore the evolution of the relationship between electricity prices and the prices of hydrocarbon resources (i.e., natural gas, and coal), and to establish their importance in determining day-ahead electricity prices in the long run. Results are depicted in Figures 6-12.

For EU countries, we find a general decrease in the role of hydrocarbon sources as electricity price drivers from the first to the second subsample. Among hydrocarbon sources, gas prices seem to reduce their influence, while coal becomes relatively more relevant.

Germany, France and the Netherlands share a common tendency: while in the first subsample the main driver for the long-run level of electricity prices is natural gas, with a minor role played by coal, in the second subsample gas prices become very weak (particularly in Germany and France) with coal increasing its effect, especially at hour 13. Notice that, differently from the other European countries, the Netherlands are characterized by a stable level of electricity demand. Thus, RES increase may be considered the principal reason for the observed change in fuel-electricity prices relations.

In Great Britain, the role of coal reduces substantially, while that of gas experiences only a slight decrease. Similar considerations hold for Spain, where coal prices become less influential and gas slightly decreases its impact with the exclusion of hour 13 that was not influenced at all by gas prices in the first subsample.

Looking at the Italian market, we notice a dramatic reduction of electricity price variation due to hydrocarbon prices at the off-peak hour. In the other hours considered, coal totally (h13) or partially (h19) substitutes gas as the main exogenous driver of electricity prices.

An interesting case of study for international comparison is Texas, where electricity demand increased (from 310TW in the first subsample to $331 \mathrm{TW}$ in the second subsample) through our sample years approximately at the same pace as RES (wind) generation. Therefore we can think that new RES generation was able to cover exactly the demand increase. Moreover, in this country gas prices were decreasing. Given this facts, we would expect a strong increase in the influence of gas prices on electricity prices. However we observe this increasing linkage only in hour 4, whereas at hours 13 and 19 gas price appears to maintain a comparable or even a slightly decreasing influence.

Summarizing our results, the first important feature that can be noticed across all countries is that for the sample 2010-2014 hydrocarbon price movements are much less relevant in determining electricity prices. The greatest part of the electricity price variance in 2006-2008 is determined by changes in gas prices, whereas coal price movements generally dominated electricity prices in 2010-2014. This must be associated with low emission prices which have favored coal in the production mixes especially in Germany, because of the nuclear phase-out decided after the Fukushima disaster. 
The fact that hydrocarbons are much less relevant in determining electricity prices over the sub-sample 2010-2014 has been explained in terms of the high RES penetration, in combination with the dynamics of demand and in terms of the different generation mix of drivers that each country shows during the two sub-samples ${ }^{18}$.

\footnotetext{
${ }^{18}$ We have further provided the evidence that most of long-run price movements for natural gas, oil and coal where largely caused by oil price changes over the period 2006-2008, but later this link vanished. However, we have decided to exclude oil from our analysis to avoid spurious results given that natural gas and crude oil have been shown to be strictly connected, see Brigida (2014).
} 

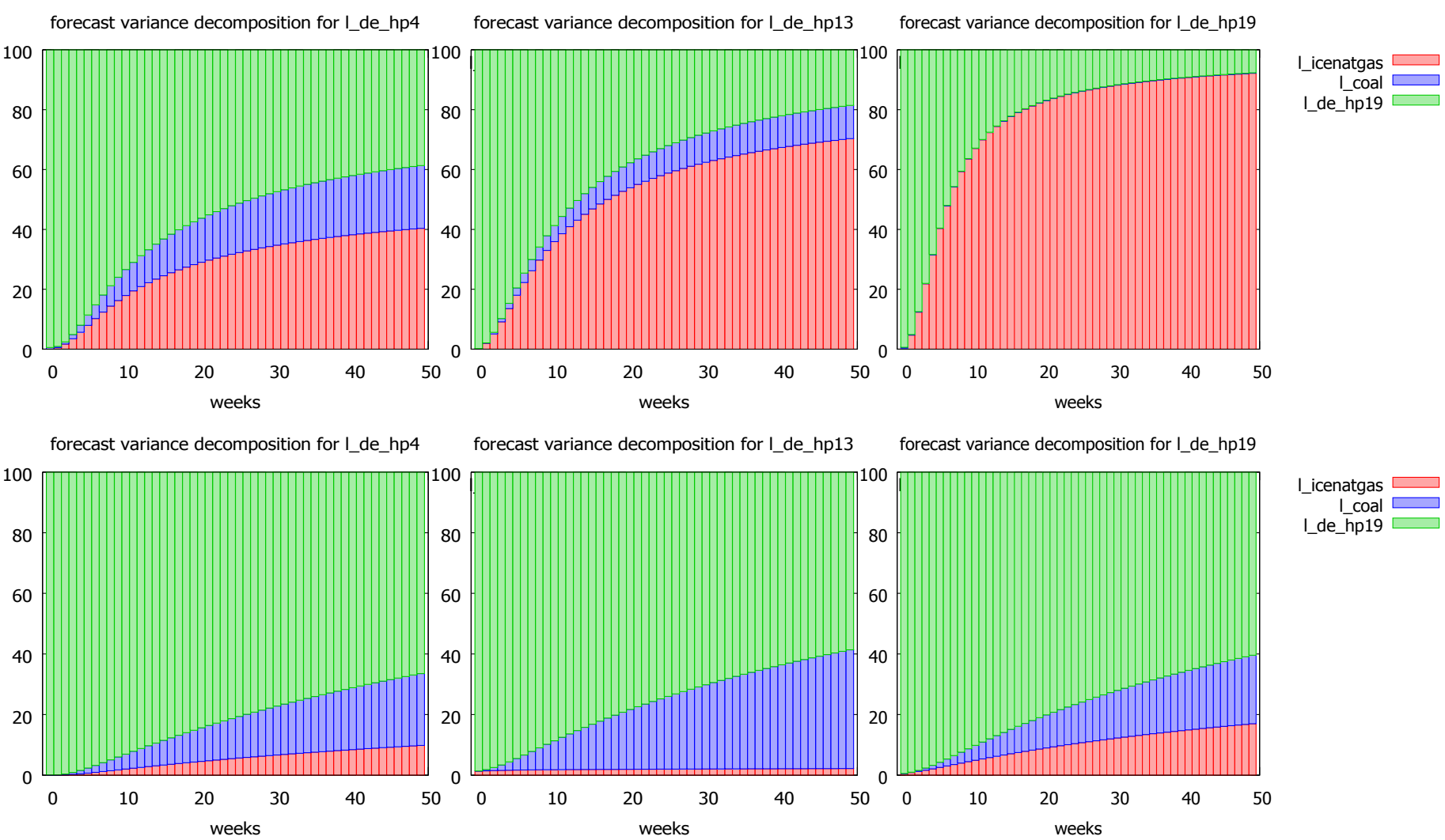

I_de_hp19

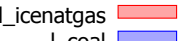

I coal $\square$

I_de_hp19

Figure 6: Variance Decomposition for hours 4 (on first column), 13 (on second column) and 19 (on third column) on sample 2006-2008 (on the first row) and on sample 2010-2014 (on second row) for Germany 

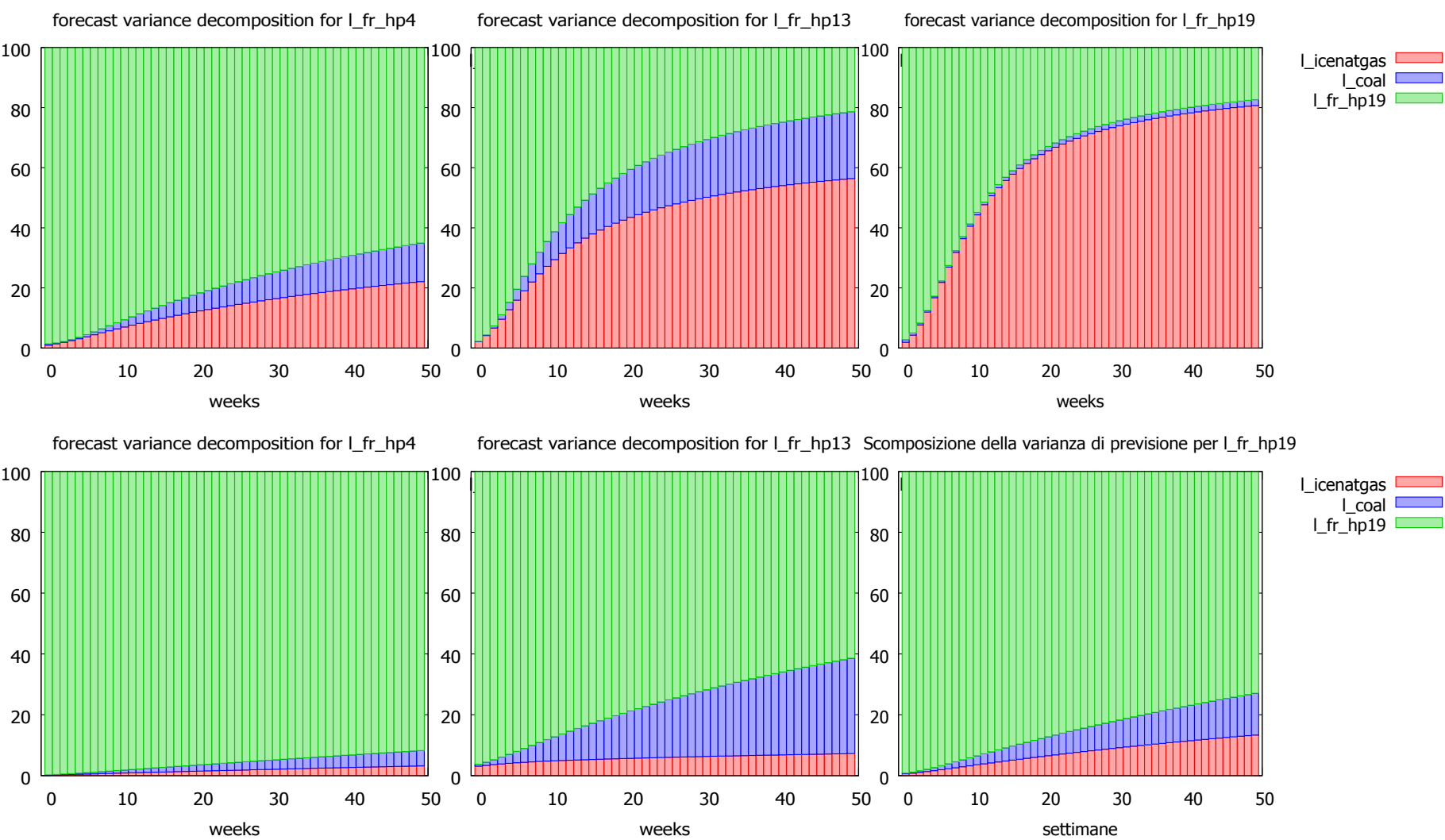

forecast variance decomposition for I_fr_hp13 Scomposizione della varianza di previsione per I_fr_hp19
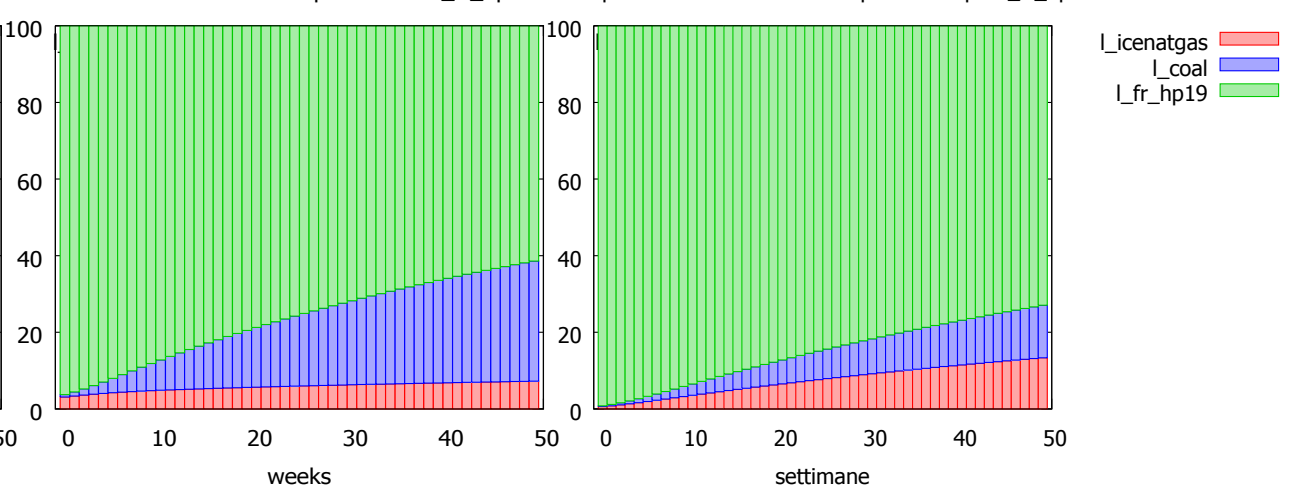

Figure 7: Variance Decomposition for hours 4 (on first column), 13 (on second column) and 19 (on third column) on sample 2006-2008 (on the first row) and on sample 2010-2014 (on second row) for France
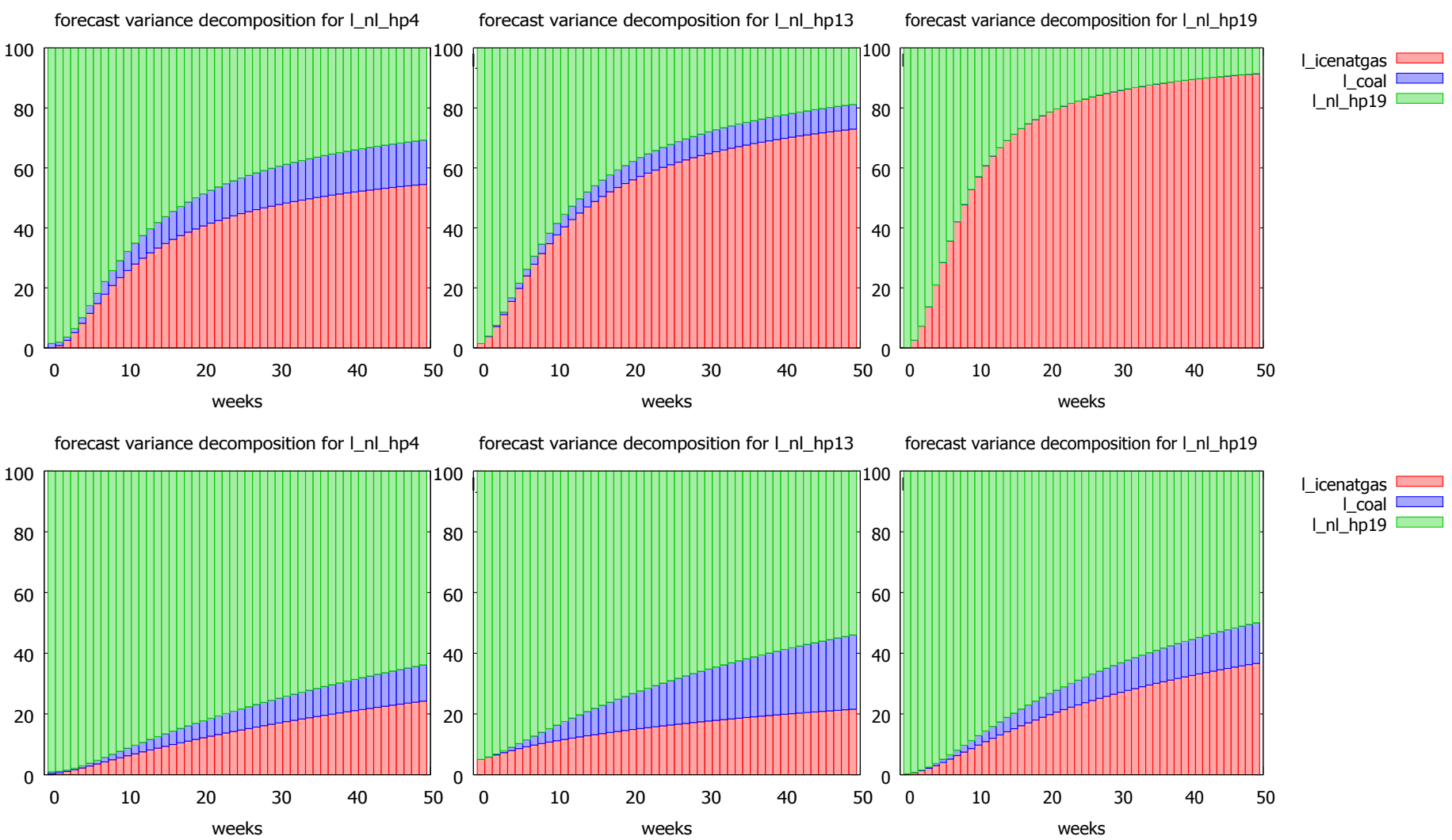

Figure 8: Variance Decomposition for hours 4 (on first column), 13 (on second column) and 19 (on third column) on sample 2006-2008 (on the first row) and on sample 2010-2014 (on second row) for Netherlands 

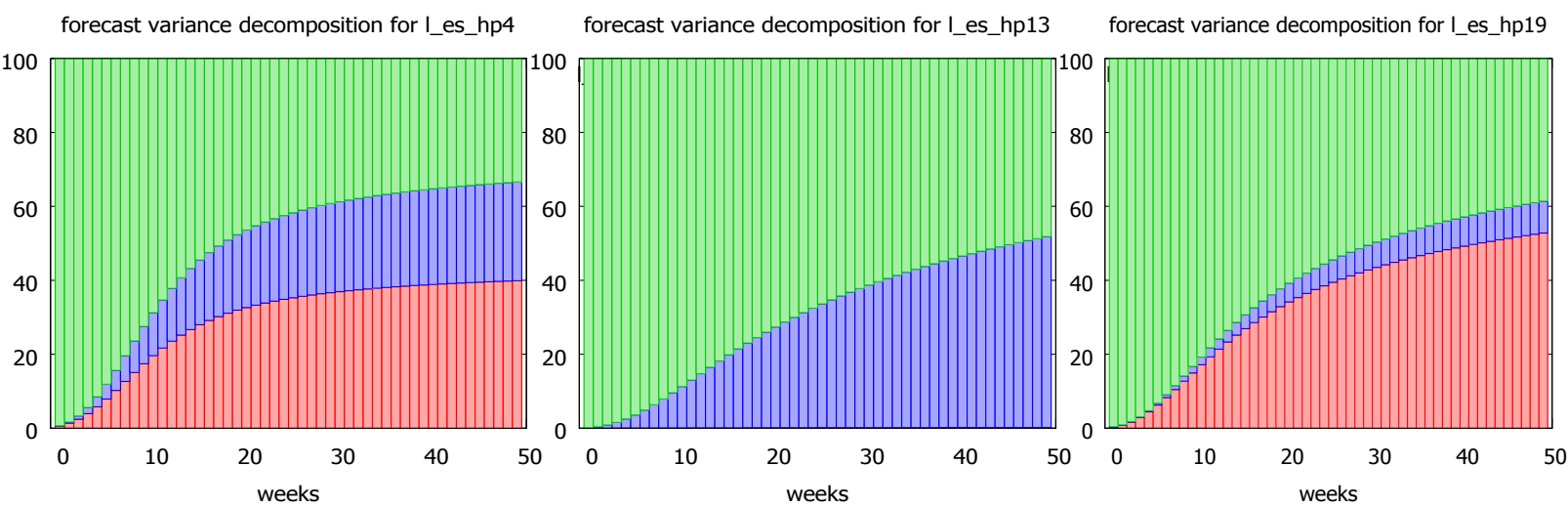

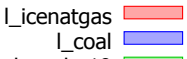

Ies hp 19
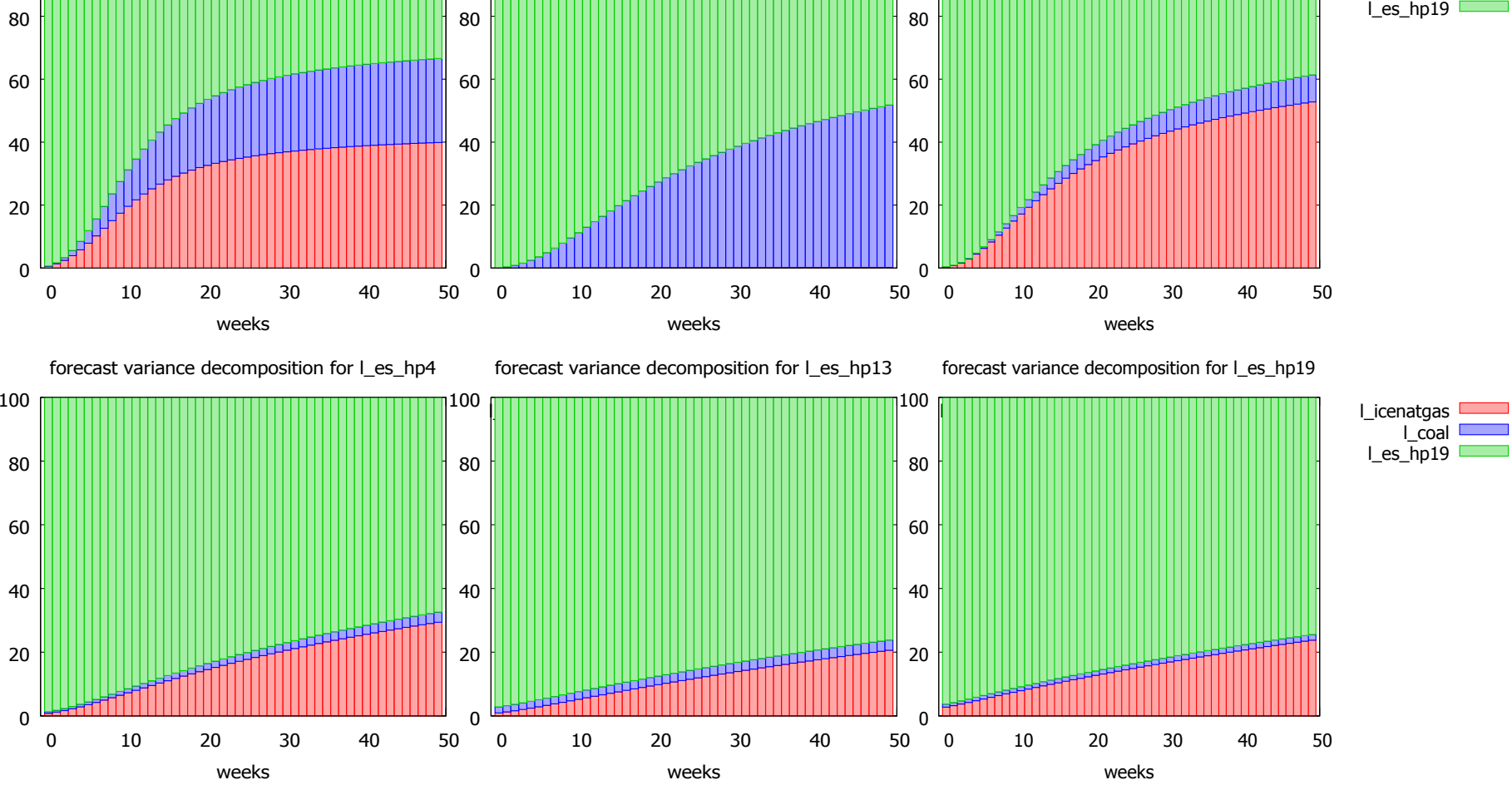

forecast variance decomposition for I_es_hp13

forecast variance decomposition for I_es_hp19
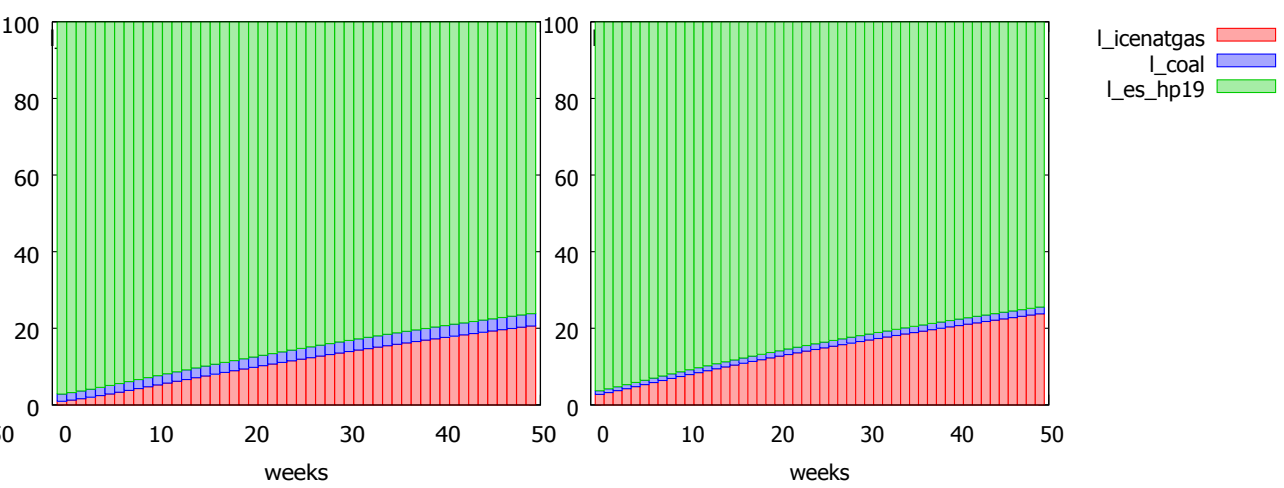

Figure 9: Variance Decomposition for hours 4 (on first column), 13 (on second column) and 19 (on third column) on sample 2006-2008 (on the first row) and on sample 2010-2014 (on second row) for Spain
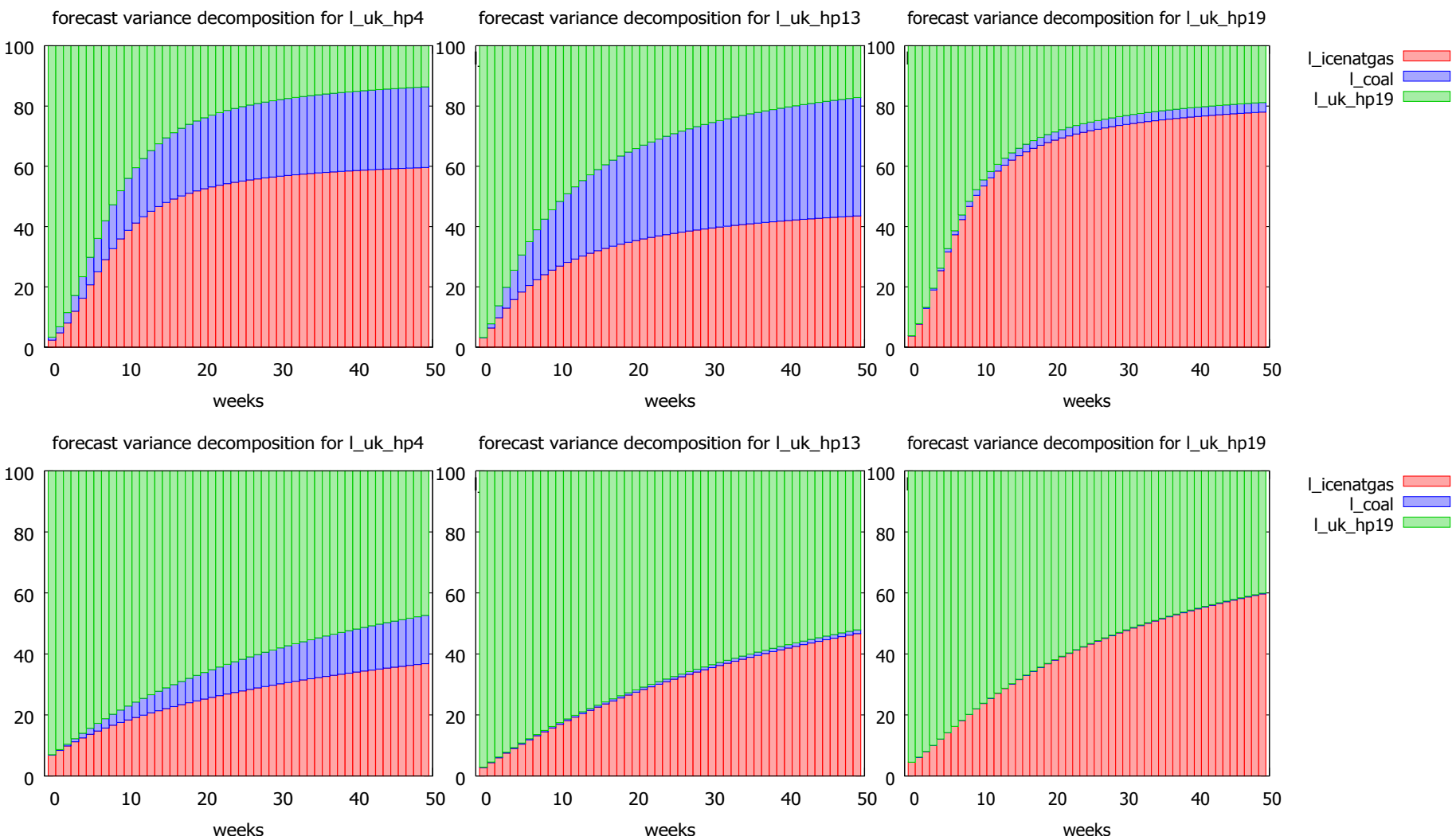

Figure 10: Variance Decomposition for hours 4 (on first column), 13 (on second column) and 19 (on third column) on sample 2006-2008 (on the first row) and on sample 2010-2014 (on second row) for Great Britain 

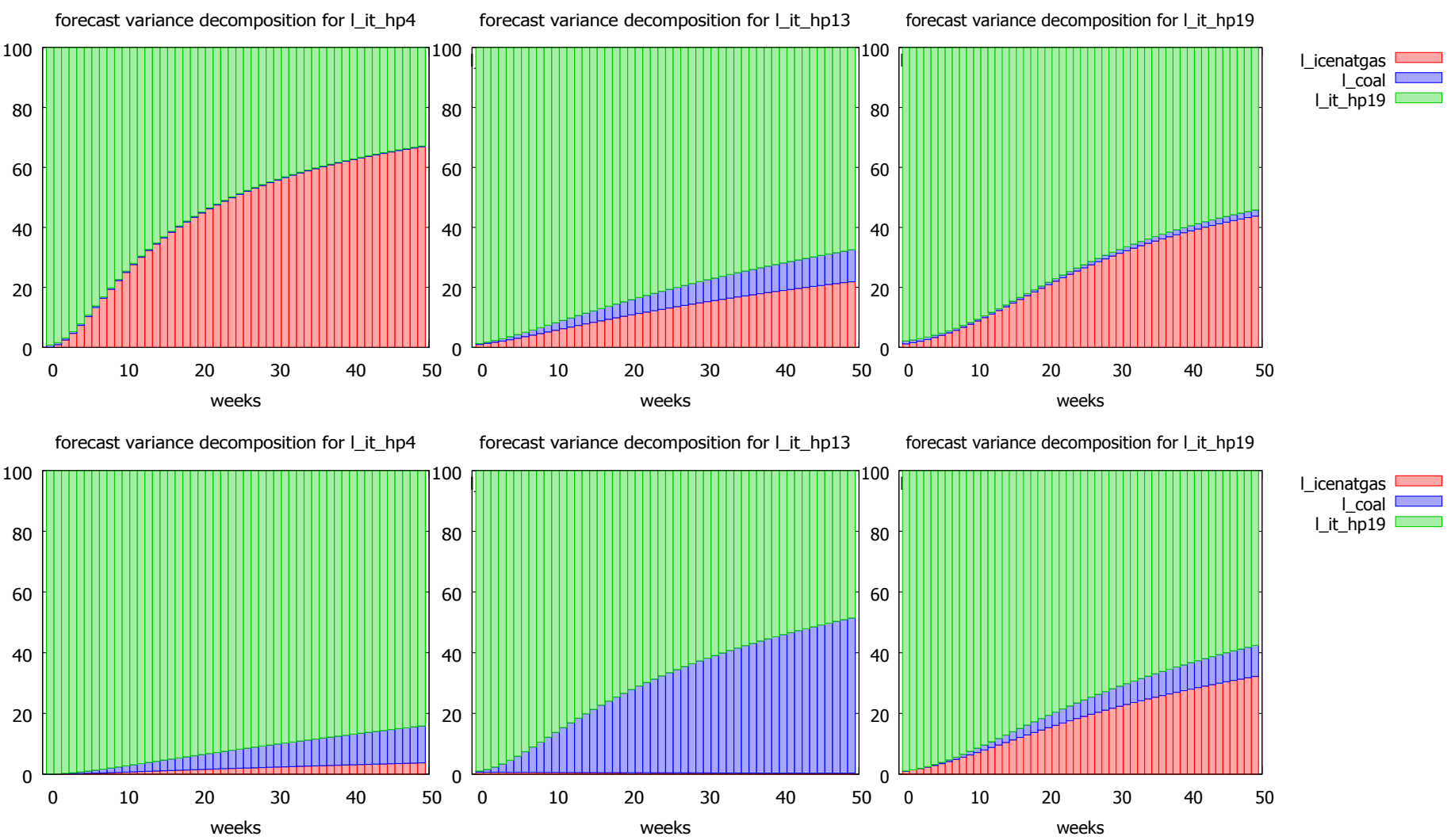

forecast variance decomposition for I_it_hp19
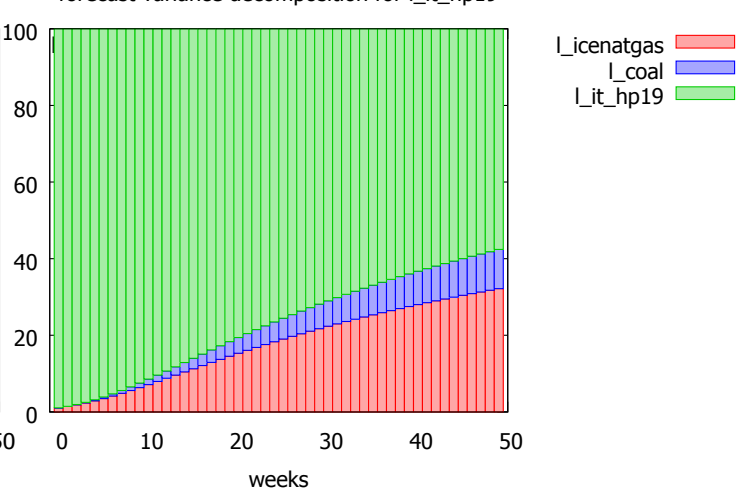

Figure 11: Variance Decomposition for hours 4 (on first column), 13 (on second column) and 19 (on third column) on sample 2006-2008 (on the first row) and on sample 2010-2014 (on second row) for Italy
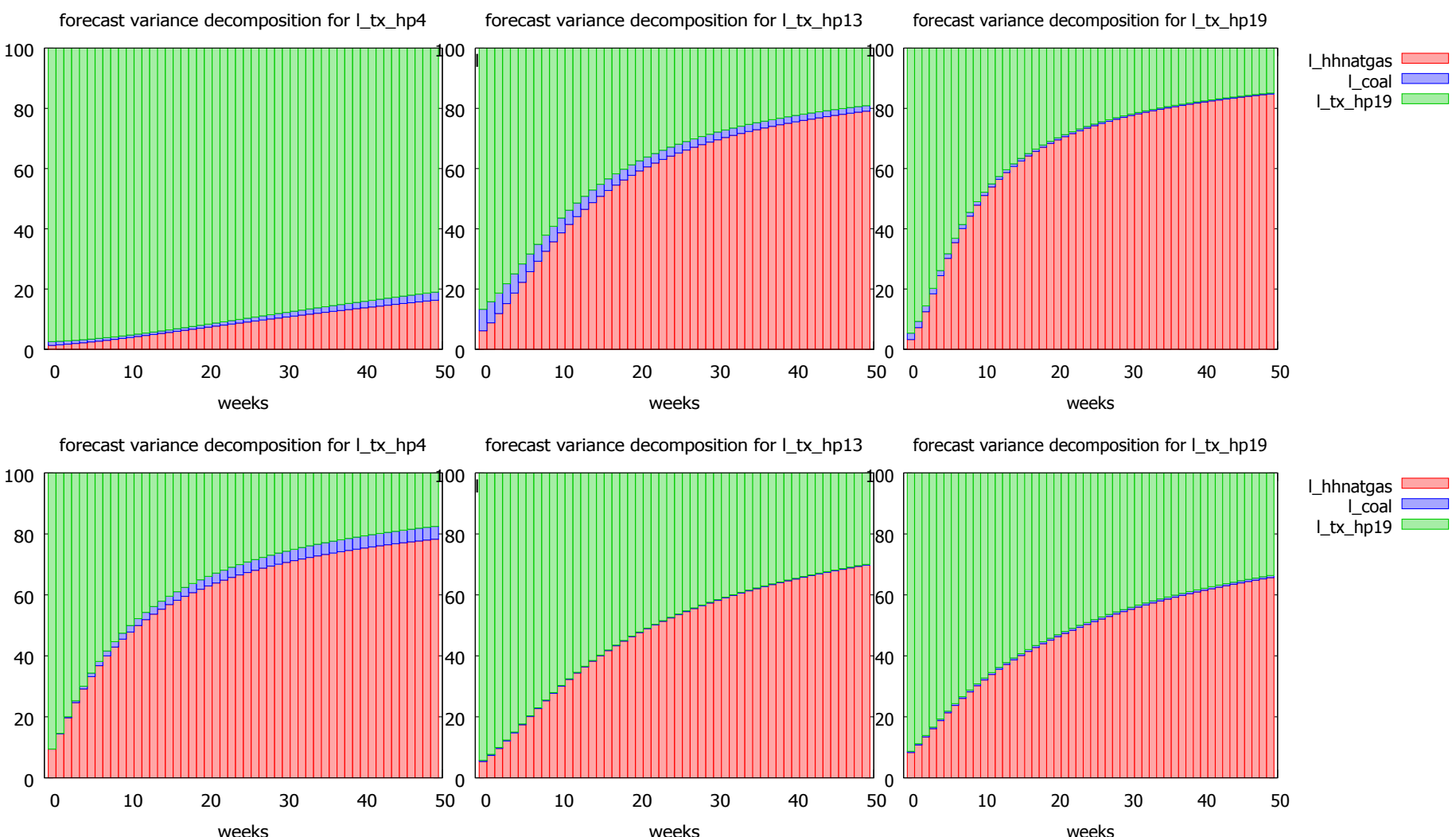

Itx

Figure 12: Variance Decomposition for hours 4 (on first column), 13 (on second column) and 19 (on third column) on sample 2006-2008 (on the first row) and on sample 2010-2014 (on second row) for Texas 


\subsection{Impacts on the Internal Energy Market}

Following the methodology described in Section 3.3, we test market (strong) integration on all pairs of EU markets according to their interconnections.

Detailed statistics are available on request and results have been summarized in Table 2, where we have compared the standard test versus the modified and more robust test. Given all previous discussion, we expect to observe two regimes for integration: one for 20062008 characterized by some integration between interconnected electricity markets and one for 2010-2014 characterized by less integration, as consequence of local policies determining different generation mixes.

Interestingly, we find two cases of maintained strong integration. The first one refers to Germany and France being integrated on both samples. This is not surprising in the light of the results described in Section 4.1, where we noticed the same evolution of the fuel/electricity price nexus in both countries. We therefore confirm the results obtained in Bosco et al. (2010) who concluded that "French and German markets seem to form a sort of core central zone"when prices up to 2007 were considered. The second case refers to France being integrated with Italy during hour 13, but not at hours 4 and 19 on 2006-2008; surprisingly, integration is detected across all hours on 2010-2014. This may be explained by higher interconnection capacity and its better exploitation due to the introduction of market coupling in the last years. See further discussion in Bunn and Gianfreda (2010) and Jerko et al. (2004).

The other results confirm instead our expectations of no integration over the second set of years characterized by high RES-E penetration. Specifically, we find no integration between Germany and The Netherlands at hour 13 (during peak period) on both samples. At hours 4 and 19, the integration found on 2006-2008 disappears in the second sample. France and Spain were integrated during the first sample at hours 4 and 19, but not at hour 13. Both markets are no more integrated for all hours in the second subsample. Moreover, France and Great Britain are integrated in the first subsample across all hours, whereas in the second sample they revert to no integration.

In line with our expectations, the effect of the strong growth of RES in EU countries is the reduction of the number of cointegration relations (i.e., strong integration among markets) during peak hours. For the off-peak hour we observe a stable number of (strongly) integrated market pairs. 


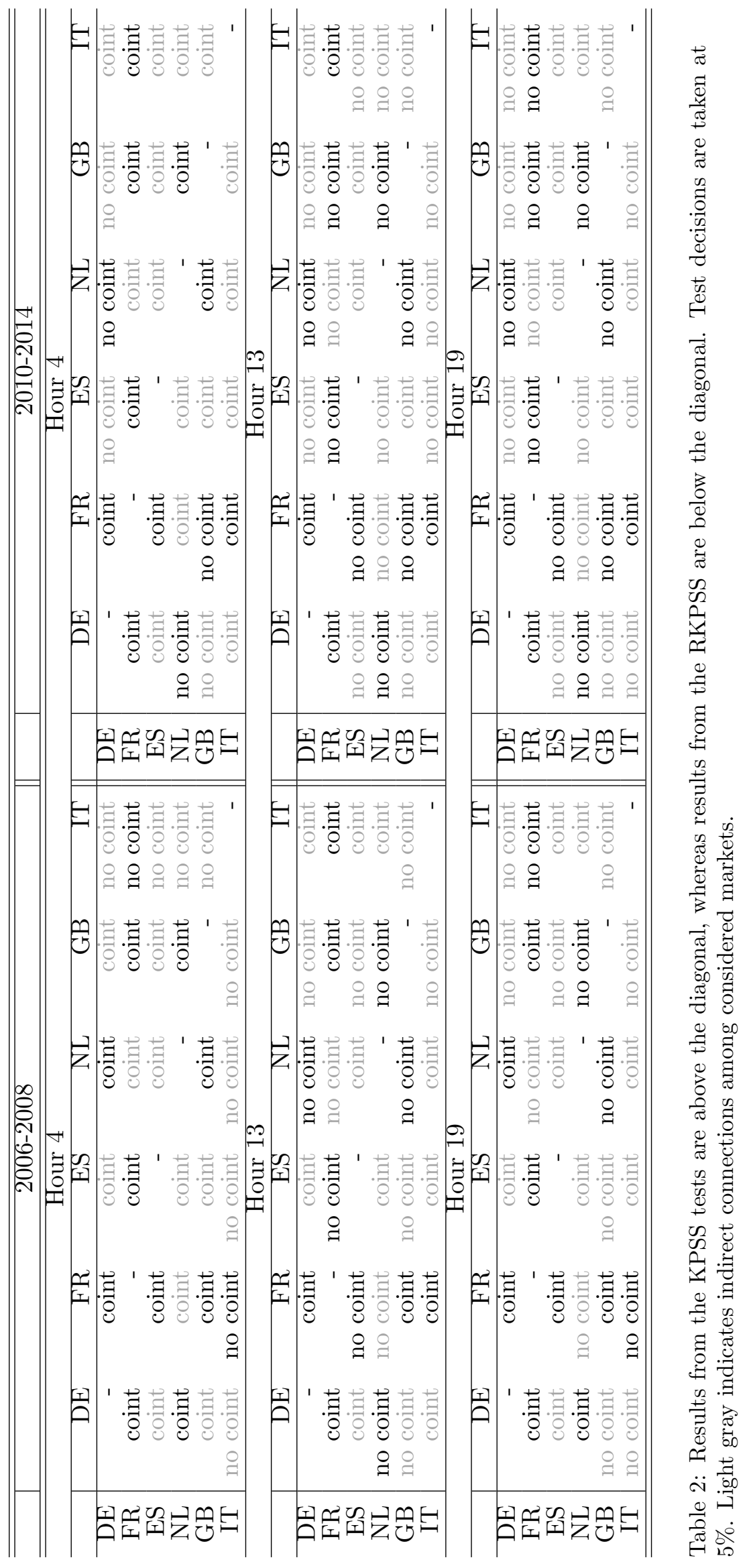




\section{Conclusions and Policy Implications}

In this paper, we have presented new evidence showing that first, the national support for RES-E generation and the induced increase in RES penetration has affected the electricityfuel nexus; secondly, this has influenced the process of integration among wholesale electricity markets already in place in the past decade. Consequently, all this has clearly shown how the overlapping of national and supranational energy policies may produce conflicting results.

Despite the high levels of RES penetration registered in several countries in the last years, previous contributions did not consider the effect of RES-E on the long-run relations between electricity prices and prices of the fundamental drivers. Other analyses were mainly oriented in testing the EU market integration as realization of the EU internal energy market policy, without taking into account the local effects of higher RES penetration on this process.

We provide for the first time the empirical evidence that the increasing RES penetration is lowering the traditional relationship between electricity and fuels (coal and gas) prices. Even if hydrocarbons remain drivers of the long-run dynamics of electricity prices, renewables are able to substantially reduce their influence. We find that coal-fired power generation has increased its influence on electricity prices, fostered by coal prices becoming relatively cheaper than natural gas prices.

The switch from natural gas, the less emission-intensive generation source, to coal raises new challenges for national and European policies for reducing greenhouse gas emissions. Following the worldwide policies for climate change, the new and stricter air pollution regulations and the competition from natural gas, we were not expecting a coal renaissance. Coal consumption is indeed increasing worldwide, as documented by BP (2015) and this is not due just to the Chinese, or Indian, or other Asian countries' economic growth. Actually coal often represents the cheapest energy option thanks to the development of a robust international coal markets. Then, the price of coal looks more appealing and makes more profitable the construction of new coal-fired power plants. However, the more coal plants are build, the harder it is to reduce the share of coal and this is a serious obstacle in mitigating climate change and global warming. Therefore, new efficient carbon emission trading schemes are called for instead of unclear, expensive and not coordinated subsidy policies to renewables which look more and more "spiraled out-of-control" billing costs paid by customers. Our results are consistent with the findings of Böhringer and Rosendahl (2010), who suggest that an increase in green generation may lower emission prices and, therefore, promote dirtier technologies as coal.

As anticipated by Holttinen (2005), Weight (2009) and Mulder and Scholtens (2013), given that electricity prices have become more connected to weather conditions and less to fossil fuels, we empirically show that market integration decreases. Our findings show that RES-E generation must not be neglected by national regulators and policy makers when legislating and planning the long-term energy future, since renewable sources are going to exhibit not only national effects but also important consequences on other European markets. As theoretically argued by de Menezes and Houllier (2015), we show empirically that isolated energy policies with RES-E targets not centrally coordinated at the EU level may interact producing divergence of electricity prices across Europe and the departure from the creation of the internal energy market.

Therefore, we strongly suggest the promotion of fully coordinated energy policies at both 
national and supranational levels and the promotion of those mechanisms able to foster coordination and enhance integration, such market coupling and grid interconnections. Even if not necessarily leading to permanent price convergence, completing the development of physical power transmissions and reinforcing existing interconnection capacity may enable an efficient balancing of power consumption and production between several market areas, urgently needed in view of increasing RES penetration which requires a more flexible and capable system.

\section{Acknowledgment}

We thank Silvester Van Koten for useful comments and suggestions. Furthermore, the DEMS visiting scholar programme at the University of Milano-Bicocca is kindly acknowledged by the first author for supporting this research project.

\section{References}

Balaguer, J. (2011). Cross-border integration in the european electricity market. evidence from the pricing behavior of norwegian and swiss exporters. Energy Policy 39(9), 4703 4712 .

Böhringer, C. and K. E. Rosendahl (2010). Green promotes the dirtiest: on the interaction between black and green quotas in energy markets. Journal of Regulatory Economics 37, $316-325$.

Bollino, A., D. Ciferri, and P. Polinori (2013). Integration and convergence in european electricity markets. Available at http://mpra.ub.uni-muenchen.de/44704/ and at SSRN2227541.

Bosco, B., L. Parisio, M. Pelagatti, and F. Baldi (2010). Long-run relations in european electricity prices. Journal of Applied Econometrics 25(5), 805-832.

BP (2015). Statistical review of energy. available at http://www.bp.com/en/global/corporate/about-bp/energy-economics/statistical-reviewof-world-energy.html (last access October 2015).

Brigida, M. (2014). The switching relationship between natural gas and crude oil prices. Energy Economics 43, 48 - 55.

Brunner, C. (2014). Changes in electricity spot price formation in germany caused by a high share of renewable energies. Energy Systems 5(1), 45-64.

Bunn, D. W. and A. Gianfreda (2010). Integration and shock transmissions across european electricity forward markets. Energy Economics 32(2), 278 - 291.

Castagneto-Gissey, G., M. Chavez, and F. D. V. Fallani (2014). Dynamic granger-causal networks of electricity spot prices: A novel approach to market integration. Energy Economics $44(0), 422-432$. 
Clò, S. and G. D'Adamo (2015). The dark side of the sun: How solar power production affects the market value of solar and gas sources. Energy Economics 49(0), 523 - 530 .

Cruz, A., A. Muoz, J. L. Zamora, and R. Espnola (2011). The effect of wind generation and weekday on spanish electricity spot price forecasting. Electric Power Systems Research $81(10), 1924-1935$.

de Menezes, L. M. and M. A. Houllier (2014). Reassessing the integration of european electricity markets: A fractional cointegration analysis. Energy Economics, -. in press.

de Menezes, L. M. and M. A. Houllier (2015). Germany's nuclear power plant closures and the integration of electricity markets in europe. Energy Policy 85, 357 - 368.

De Vany, A. and W. Walls (1999). Cointegration analysis of spot electricity prices: insights on transmission efficiency in the western US. Energy Economics 21(5), 435 - 448.

Dickey, D. A. and W. A. Fuller (1979). Distribution of the estimators for autoregressive time series with a unit root. Journal of the American Statistical Association 74(366), 427-431.

EU (2009). Directive 2009/28/ec of the european parliament and of the council of 23 april 2009 on the promotion of the use of energy from renewable sources and amending and subsequently repealing directives 2001/77/ec and 2003/30/ec.

EU Commission (2014a). Communication from the commission to the european parliament, the council, the european economic and social committee and the committee of the regions. a policy framework for climate and energy in the period from 2020 to 2030.

EU Commission (2014b). Quarterly report on european electricity markets. Technical Report Vol 7 (3), DG Energy.

Gelabert, L., X. Labandeira, and P. Linares (2011). An ex-post analysis of the effect of renewables and cogeneration on spanish electricity prices. Energy Economics 33, Supplement 1(0), S59 - S65. Supplemental Issue: Fourth Atlantic Workshop in Energy and Environmental Economics.

Gianfreda, A. and L. Parisio (2015). RES effects in italian wholesale electricity market. In 12th International Conference on the European Energy Market (EEM), 2015.

Harvey, A. C. and S. J. Koopman (1992). Diagnostic checking of unobserved-components time series models. Journal of Business \& Economic Statistics 10(4), 377-389.

Holttinen, H. (2005). Impact of hourly wind power variations on the system operation in the nordic countries. Wind Energy 8, 197-218.

Huisman, R. and M. Kilic (2013). A history of european electricity day-ahead prices. Applied Economics 45, 2683-2693.

IEA (2013). World energy outlook $2013 . \quad$ Available at http://www.worldenergyoutlook.org/publications/weo-2013/. 
Jerko, C. A., J. Mjelde, and D. A. Bessler (2004). Identifying Dynamic Interactions in the Western US, Chapter 9 in part III, in Modelling Prices in Competitive Electricity Markets, Bunn D. (Editor). Wiley, ISBN: 978-0-470-84860-9.

Ketterer, J. C. (2014). The impact of wind power generation on the electricity price in germany. Energy Economics 44(0), $270-280$.

Kwiatkowski, D., P. C. B. Phillips, P. Schmidt, and Y. Shin (1992). Testing the null hypothesis of stationarity against the alternative of a unit root: How sure are we that economic time series have a unit root? Journal of Econometrics 54(1-3), 159-178.

Lindström, E. and F. Regland (2012). Modeling extreme dependence between european electricity markets. Energy Economics 34(4), 899 - 904.

Mauritzen, J. (2013). Dead battery? wind power, the spot market, and hydropower interaction in the nordic electricity market. Energy Journal 34(1), $103-123$.

Mulder, M. and B. Scholtens $(2013,9)$. The impact of renewable energy on electricity prices in the netherlands. Renewable Energy 57, 94-100.

Pelagatti, M. M. and P. K. Sen (2013). Rank tests for short memory stationarity. Journal of Econometrics 172(1), 90-105.

REN21 (2015). Renewables 2015 - global status report. ISBN 978-3-9815934-7-1.

Said, S. E. and D. A. Dickey (1984). Testing for unit roots in autoregressive-moving average models of unknown order. Biometrika 71(3), 599-607.

Weight, H. (2009). Germany's wind energy: the potential for fossil capacity replacement and cost saving. Applied Energy 86, 1857-1863.

Woo, C., I. Horowitz, J. Moore, and A. Pacheco (2011). The impact of wind generation on the electricity spot-market price level and variance: The texas experience. Energy Policy 39(7), 3939 - 3944. Special Section: Renewable energy policy and development.

Woo, C., J. Zarnikau, J. Moore, and I. Horowitz (2011). Wind generation and zonal-market price divergence: Evidence from texas. Energy Policy 39(7), 3928 - 3938. Special Section: Renewable energy policy and development. 